\title{
Economia Solidária - novos caminhos. Redesenhando a sociedade e repensando os modelos tradicionais: é hora de mudar?
}

\author{
Solidarity Economy - new paths
}

\section{Antonio Gabriel Antico Neves} antonioanticoneves@hotmail.com

Graduando em Letras pela Pontifícia Universidade Católica do Rio de Janeiro PUC-Rio.

\begin{abstract}
Resumo
Este artigo busca a analisar os novos caminhos para a economia solidária e a necessidade de repensar os modelos tradicionais. Em meio aos tempos de pandemia e crises ambientais, nunca antes o homem acumulou tantas riquezas. Em contrapartida, esperava-se a erradicação da pobreza, quando se vê o contrário. Cada vez mais a distância entre os dois mundos se consolida.
\end{abstract}

Palavras-chave: Economia; crise; pobreza; trabalho; ética.

\begin{abstract}
This article pursues to analyze the new paths for which the solidarity economy can thrive and the necessity to rethink our traditional ways of profit and labor. With the economic crisis and the environmental crisis, never a man was able to accumulate such huge riches, and nonetheless, never was a part of our population so poor. The distance between the two worlds has never been so cruel.
\end{abstract}

Keywords: economy; crisis; poverty; job; ethic. 
NEVES, Antonio Antico Neves. Economia Solidária - novos caminhos. Redesenhando a sociedade e repensando os modelos tradicionais: é hora de mudar? Dignidade Re-Vista, v.6, n.11, dez 2020.

\section{DIGNIDADE}

\section{Introdução}

Há o tempo do progresso e há o tempo de repensar o progresso. O ano de 2020 foi marcado pelas calamidades públicas: a pandemia, os desastres naturais, as queimadas somadas às guerras do leste Europeu nos dão um aviso de que algo não está correto na forma em que gerimos o mundo. E não só em nossas atitudes perante nossos semelhantes, mas de todo um sistema econômico que está fadado às contradições. Um sistema econômico que reitera uma hegemonia milenar e faz com que cada vez mais os humanos se preocupem somente consigo mesmos. Nossa atividade na Terra precisa ser repensada, nossos impactos, recalculados; é necessário que enxerguemos o mundo de forma holística. Para cada medida de ação, há uma retaliação.

Vejamos os cenários atuais econômicos e a concentração das riquezas. O "dinheiro" nunca é questionado, nossos modelos econômicos amplamente disseminados e respeitados em toda a parte do mundo. E ninguém se questiona quanto à validade daquele papel moeda, ou mais ainda: porque o que eu tinha ontem, já não vale mais nada. A verdade é que o tempo passa, infelizmente, e assim como o tempo passa, o dinheiro passa a valer menos, cada vez menos: é a inflação - os economistas argumentariam, e de fato é, mas o que mais está em jogo? O que antes eu comprava com um terço do que tenho, hoje preciso do valor integral para a mesma compra. E não é como se ganhássemos mais. Pelo contrário, os reajustes, na maioria das vezes, são insignificantes e sempre vêm acompanhados de uma medida maior de financiamento.

E não é como se meu poder de compra tivesse aumentado, o que aumenta é minha capacidade de financiamento, que acarreta um consumismo ainda maior, e, consequentemente, dívidas ainda maiores. O que termina por aumentar ainda mais o problema econômico; e o grande culpado de tudo isso: a dívida. Uma pesquisa recente da XP estima que $45 \%$ da população brasileira esteja hoje no "vermelho", isso é quase metade do país endividado. Em outras palavras: o sonho dos bancos, as grandes fortunas existem sob a consolidação das dívidas. Quando 26 pessoas detêm um patrimônio equivalente ao da metade da população mais pobre do mundo, há algo de muito errado nessa conta. 
NEVES, Antonio Antico Neves. Economia Solidária - novos caminhos. Redesenhando a sociedade e repensando os modelos tradicionais: é hora de mudar? Dignidade Re-Vista, v.6, n.11, dez 2020.

\section{DIGNIDADE}

\section{Fundamentação}

A pandemia, para grande parte da população, foi no mínimo desafiadora, remodelou nossos costumes, trouxe a "falta" como uma presença constante em nossas vidas. Aprendemos mais uma vez a "dar um jeitinho" (de forma positiva) como sempre damos, refazendo aquela conta, guardando um pouco mais, ajudando o vizinho; a recessão virou uma forma de rotina e nos acostumamos a ela. Em todo caso, uma parcela da população mundial lucrou de forma devastadora durante a pandemia, de forma nunca antes vista. Para o seleto grupo dos bilionários mundiais, a pandemia registrou um aumento de $27 \%$ em suas fortunas, de acordo com dados da PWC, ultrapassando a marca de US\$ 10 trilhões (representa quase 3 vezes a riqueza do Brasil estimada em US\$ 3,54 trilhões) acumulados até julho, um verdadeiro recorde. E o mais impressionante são os seus setores de atuação, os bilionários da saúde e tecnologia (os mais lucrativos durante a crise da Covid-19) viram seus ganhos ultrapassarem a marca dos $40 \%$, e não por coincidência.

Em meio a tudo isso: a pobreza. Uns com tão pouco e outros com mais do que podem contar. Pela primeira vez, desde 1998, a pobreza extrema deve crescer, estima-se que até o final do ano mais de 115 milhões de pessoas estarão contempladas nessa lista negra da economia. E como se configura exatamente essa lista? Enquanto uns têm patrimônios acumulados em mais de bilhões de dólares, outros vivem com menos de US\$1,90 por dia. Antes do ano de 2020 e da fatídica pandemia, esperava-se de que a pobreza no mundo diminuísse para 7,9\% da população mundial, hoje os dados mais otimistas estimam até o fim do ano que $9 \%$ da população mundial esteja nesse nível de pobreza extrema. A meta global estabelecida pelo Banco Mundial em 2013 era de 3\%.

Esperava-se que com o advento das tecnologias estivéssemos mais próximos uns dos outros e, por consequência, mais dispostos a ajudar. No entanto, toda ajuda empresarial - na maioria das vezes - se configura como uma estratégia de marketing afim de angariar uma disputada parcela de mercado. A economia não pode estar dissociada da população, e mais, a economia não pode ser um jargão de distanciamento e nem um mecanismo elitista. 


\section{DIGNIDADE}

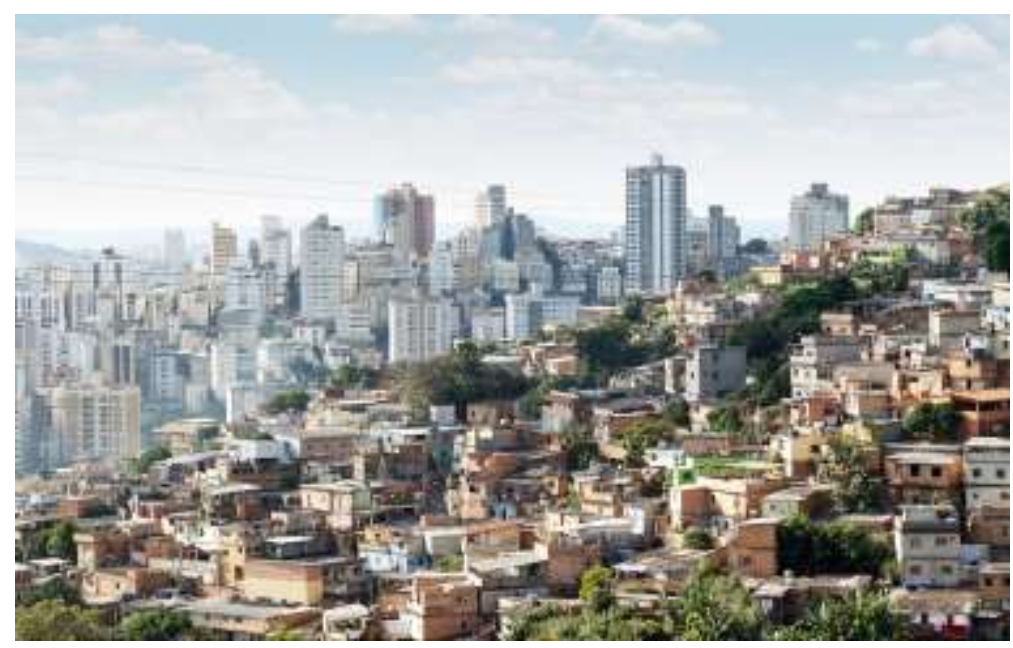

Figura 1: A distância física x a distância econômica.

O rico cada vez mais rico e o pobre cada vez mais pobre. É esse o nosso modelo econômico. E os argumentos sempre fundamentados sobre alicerces insustentáveis como a meritocracia, o capitalismo e a lei da selva - todos pautados sob a ótica do individualismo. A verdade é que já deixamos nossas características de animais para trás há muito tempo e ainda assim insistimos na lei do mais forte como forma de sobrevivência; por que não cooperar?

Hoje somos condecorados com diplomas dos saberes mais variados, entre doutorados, as formações tradicionais, e, no entanto, não há um somente que questione nossa forma de economia. E não digo a respeito de política e posicionamento, mas seguindo um pensamento macro, nossa forma de gestão é insustentável, nossos recursos finitos, enquanto a ganância do homem rompe a barreira dos sonhos. E de geração em geração, os mesmos erros se repetem e o mesmo desejo se instaura naquele pai que não deseja, propriamente, um mundo melhor para todos, mas para seu filho. Ou melhor: para aqueles que se firmaram nesse modelo, seja por meio duma herança abastada ou pelo prazer da sorte e da boa formação acadêmica - a quem foi concedido esse espaço -, o egoísmo repreende qualquer medida de compaixão. E somos levados a crer que isso é bom, de que "fazemos nossa parte" - não que eu seja contra um projeto de vida, mas como pensar num papel isolado quando o outro não tem nem o que comer?

Portanto, há que buscarmos uma nova forma de economia e aliados a esse novo modelo: uma nova forma de conduta. A economia solidária surgiu como conceito no final do século passado e reitera a "ideia solidária no sistema produtivo em contraposição à ideia do capitalismo individual-competitivo das sociedades neoliberais capitalistas” (Singer, 2003, p.166). Uma nova economia em que produtores, prestadores de serviço, consumidores, credores se relacionam baseados em conceitos democráticos e moralmente justos (autogestão) 
NEVES, Antonio Antico Neves. Economia Solidária - novos caminhos. Redesenhando a sociedade e repensando os modelos tradicionais: é hora de mudar? Dignidade Re-Vista, v.6, n.11, dez 2020.

\section{DIGNIDADE}

promovendo a solidariedade entre os membros. É como se a mão invisível (teoria econômica de que o mercado é capaz de autorregular-se sem necessidade de intervenção) estivesse cansada de sustentar uma força desigual e agora cabe a nós mesmos reinventar e sustentar a economia de uma forma justa e sustentável, uma forma mais solidária e consciente.

Por todos os lados há quem faça a diferença e os pioneiros dessa nova economia já estão em atuação, mas ainda é preciso muito esforço para espantar os fantasmas do passado, ou melhor: os fantasmas do lucro. Temos como exemplo, no Ceará, um representante da ES economia solidária, o Banco Palmas, situado no Conjunto Palmeiras, bairro da periferia da cidade de Fortaleza. A associação de moradores local implementou um banco comunitário para a geração de trabalho e promoção de empreendimentos seguindo o modelo de economia solidária. Talvez o primeiro banco do "bem" no mundo. O Banco Palmas é um dos exemplos de economia solidária de mais importância no mundo. Além de ir contra toda a concepção atual dos bancos e do modelo de sócios, ações e lucro - um modelo fadado à dívida que assoma cada vez mais endividados. E para o raciocínio bancário tradicional, se uma ponta se endivida a outra ponta lucra.

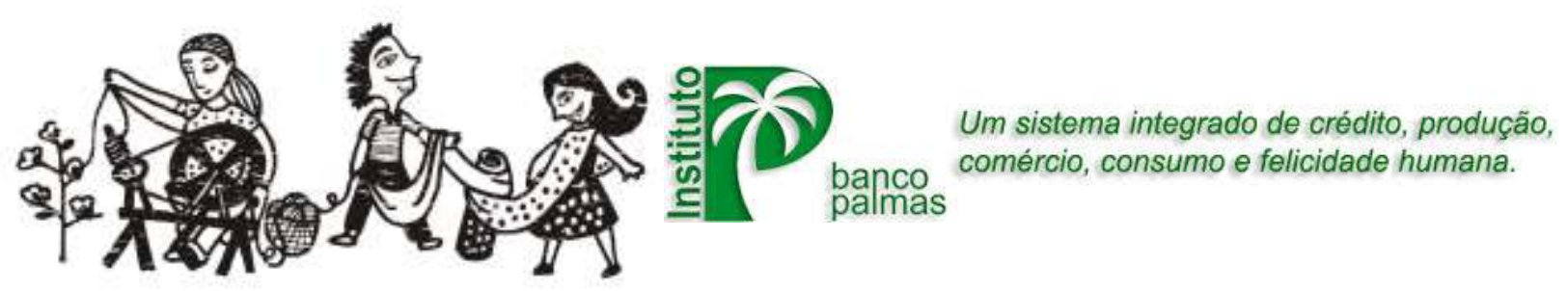

Figura 2: Imagem que configura o conceito de economia solidária e, ao lado, logo e slogan do Banco Palmas.

O Banco Palmas é um marco para entendermos que mudar não é somente necessário, como muito possível. Ele é pioneiro na emissão de "moeda social" e fornecimento de crédito para a população de baixa renda, sem incidência de juros (quase nulo) e sem a burocracia preconceituosa dos bancos tradicionais. Além de tudo isso, o Banco Palmas não possui dono, configura-se como uma instituição financeira sem fins lucrativos - uma contradição bonita pertencente aos moradores do Conjunto Palmeiras, que podem decidir sobre seu rumo em assembleias abertas a todos os moradores da região. 
NEVES, Antonio Antico Neves. Economia Solidária - novos caminhos. Redesenhando a sociedade e repensando os modelos tradicionais: é hora de mudar? Dignidade Re-Vista, v.6, n.11, dez 2020.

\section{DIGNIDADE}

\section{Conclusão}

Devemos nos atentar às armadilhas, pois há quem discorde e há quem limite os conceitos de economia solidária a somente uma lacuna a ser preenchida no sistema capitalista - e não como um novo sistema em si, "como uma forma de ocupar os desocupados, com uma terapia ocupacional para aqueles que são excluídos do mercado formal” (Shutz, 2008, p.49). Seguindo esta corrente de pensamento limitadora, a economia solidária pode ser diminuída a uma mera estratégia capitalista, "rebaixando as próprias condições de trabalho e salários, transformando os trabalhadores em exploradores de si mesmos" (Martins, 2008, p.11). Portanto, sejamos claros e incisivos, pensar a economia solidária seguindo os moldes do capitalismo selvagem já existente não funciona, devemos repensar também nossa cultura, nosso individualismo, nossos paradigmas. O que acarreta problemas ainda maiores em países subdesenvolvidos em que a educação básica não é disseminada de uma forma consolidadora.

Atentemo-nos à cronologia das consequências: a economia solidária como sistema efetivo só é possível em uma sociedade igualitária, em que os bens principais como educação, segurança e saúde são garantidos ao povo, mas isto não impede sua implementação aos poucos. É como uma mudança de paradigma que tem de acontecer, de todo um sistema injusto e insustentável firmado sobre concepções do "trabalho libertador" que, na verdade, sob condições precárias, escraviza o homem; e aqueles que nem a isso têm acesso são obrigados a viver à margem de todos os avanços, como uma sociedade do século XVII em pleno século XXI, longe de notícias, de saneamento básico, longe dos livros e de um entendimento maior.

A mudança tem de começar conosco, por isso o grande argumento contrário à economia solidária é a falta de adesão; mas há uma mudança de paradigma acontecendo e cada vez mais as empresas são obrigadas - ainda que somente superficialmente e sob os holofotes do marketing - a investimentos sociais. É o início de um novo tempo - talvez no fim de tudo possamos identificar os culpados, ainda que não seja necessário - o essencial é sabermos que toda forma de vida é conectada, que a riqueza extrema de um significa a pobreza extrema do outro. A nossa economia tem de ser polivalente e holística, devemos pensar o mundo e a raça humana como uma coisa só, sem os limites de fronteiras ou de raça, respeitando todos os seres do planeta e entendendo de forma ampla a nossa responsabilidade conosco. Temos de reconhecer nossa supremacia como espécie evolutiva, mas toda supremacia deve vir acompanhada de um reconhecimento de responsabilidade e, depois, de um reconhecimento de 
NEVES, Antonio Antico Neves. Economia Solidária - novos caminhos. Redesenhando a sociedade e repensando os modelos tradicionais: é hora de mudar? Dignidade Re-Vista, v.6, n.11, dez 2020.

\section{DIGNIDADE}

impacto. Qual é o legado que queremos deixar como espécie? Qual é o legado que iremos deixar para aqueles que ainda não nasceram? Ajamos para que o futuro não seja como antigamente. Nenhuma mudança começa de uma hora para a outra, mas a economia solidária é uma nova forma de interpretar antigos fundamentos, utilizando aquilo que nos firmou como espécie predominante: o trabalho em equipe. 
NEVES, Antonio Antico Neves. Economia Solidária - novos caminhos. Redesenhando a sociedade e repensando os modelos tradicionais: é hora de mudar? Dignidade Re-Vista, v.6, n.11, dez 2020.

\section{DIGNIDADE}

\section{Referências bibliográficas}

O Que é Economia Solidária? Aventura De Construir. Disponível em: aventuradeconstruir.org.br/o-que-e-economiasolidaria/?gclid=CjwKCAjwz6_8BRBkEiwA3p02VQ8Y5fl8CWsWXz_BCPuEYOXmU4O2 A_zOdxHOcc6_x67VaWEl5k_RXhoC6B0QAvD_BwE. Acesso em: 4 nov 2020.

BARROS, Rodrigo. Pesquisa Mostra Que 63 Milhões De Brasileiros Estão No Vermelho. Folha PE, 26 abr 2019. Disponível em: www.folhape.com.br/economia/pesquisa-mostra-que63-milhoes-de-brasileiros-estao-no-vermelho/103111/. Acesso em: 12 set 2020.

Patrimônio Dos 26 Mais Ricos Do Mundo Equivale Ao Da Metade Mais Pobre. Agência Brasil, 22 jan 2019. Disponível em: agenciabrasil.ebc.com.br/economia/noticia/201901/patrimonio-dos-26-mais-ricos-do-mundo-e-igual-ao-da-metade-mais-pobre. Acesso em: 5 out 2020 .

Armênia x Azerbaijão: Por Que Há Uma Guerra Acontecendo No Leste Da Europa.” BBC News Brasil, 1 out 2020. Disponível em: www.bbc.com/portuguese/internacional-54379493. Acesso em: 6 nov 2020.

CARBINATTO, Bruno. Bilionários Ficaram Quase 30\% Mais Ricos Durante a Pandemia. Superinteressante, 7 out 2020. Disponível em: super.abril.com.br/sociedade/bilionariosficaram-quase-30-mais-ricos-durante-a-pandemia/. Acesso em: 4 nov 2020.

"Economia Solidária Pós-Pandemia Deve Pautar Os Governos Progressistas." Vermelho, 18 May 2020, vermelho.org.br/2020/05/18/economia-solidaria-pos-pandemia-deve-pautar-osgovernos-progressistas/.

LELLES, Ana Raquel. Efeitos da pandemia: dívidas preocupam $45 \%$ da população. Estado de Minas, 4 abr 2020. Disponível em: www.em.com.br/app/noticia/economia/ 2020/04/04/internas_economia,1135534/efeitos-da-pandemia-dividas-preocupam-45-dapopulacao.shtml. Acesso em: 12 set 2020.

MACIEL, Camila. Patrimônio dos 26 mais ricos do mundo equivale ao da metade mais pobre. Agência Brasil, 21 jan 2019. Disponível em: agenciabrasil.ebc.com.br/economia/noticia/2019-01/patrimonio-dos-26-mais-ricos-do-mundoe-igual-ao-da-metade-mais-pobre. Acesso em 4 fev 2020.

POCHMANN, Marcio. Economia solidária pós-pandemia deve pautar os governos progressistas. Vermelho, 18 maio 2020. Disponível em: vermelho.org.br/2020/05/18/economia-solidaria-pos-pandemia-deve-pautar-os-governosprogressistas/. Acesso em: 10 ago 2020.

SILVA, Marcia. A economia solidária e as novas possibilidades do mundo do trabalho. Âmbito Jurídico, 30 nov 2001. Disponível em: ambitojuridico.com.br/edicoes/revista-100/aeconomia-solidaria-e-as-novas-possibilidades-do-mundo-do-trabalho/. Acesso em: 10 jan 2020 . 
NEVES, Antonio Antico Neves. Economia Solidária - novos caminhos. Redesenhando a sociedade e repensando os modelos tradicionais: é hora de mudar? Dignidade Re-Vista, v.6, n.11, dez 2020.

\section{DIGNIDADE}

VALLE, Paulo. Economia solidária: o que é e qual seu impacto? Blog do Sebrae Santa Catarina, 5 jul 2018. Disponível em: blog.sebrae-sc.com.br/economia-solidaria-o-que-e/. Acesso em: 3 jan 2020. 